\title{
FUZZY-LOGICAL APPROACH TO CONSTRUCTING AN INTEGRAL INDICATOR IN A LEVEL ESTIMATION MODEL SIGNIFICANT MARKET ADVANTAGE
}

\author{
Valentin Myachin ${ }^{1}$, Olena Yudina²
}

\begin{abstract}
The purpose of this research is to construct fuzzy expert system to estimate an integral degree of market concentration by fuzzy-logical approach. The methodological basis of the study consists of scientific works of domestic and foreign scientists and leading specialists, statistical and analytical materials of state authorities. Fuzzy Inference is introduced for the integrated indicator construction. Two indicators are chosen as input variables. The first indicator, $C R$, is a level of concentration ratio. The second indicator, $H H I$, is the Herfindahl-Hirschman index. Output variable, $M C$ indicator, means a degree of market concentration. Both input and output variables are transformed to fuzziness through the construction of membership function. The function type and parameters are substantiated and "bell"-shaped membership function to describe uncertainty of the values falling under normal distribution is chosen. The quantity of fuzzy sets at every input is considered $z=3$ and the quantity of input variables is considered $\omega=2$. To achieve completeness of the model, the quantity of logic rules is considered $r=3^{2}=9$. To calculate a degree of market concentration, Mamdani fuzzy conclusion is applied. Defuzzification is engaged to calculate value of the output variable which is $M C$ indicator to mean a degree of market concentration and therefore readiness to implement the innovation strategy for enterprises active in innovation. To estimate a degree of market concentration, the fuzzy expert system given allows for engagement of different indicators due to fuzzy logic methodology which considers fuzziness of the input and output variables. The construction of an integral indicator for assessing the state of economic competition in order to establish the feasibility of identifying operators and providers with a significant market advantage will improve the assessment of the state of economic competition in the market in the telecommunications services market in Ukraine.
\end{abstract}

Key words: monopolization of the market, market concentration coefficient, the Herfindahl-Hirschman index, fuzzy expert system, fuzzy logic, membership function, defuzzification.

JEL Classification: B21, B41, C65, D41, D42, D43

\section{Introduction}

The aggravation of competition in highly competitive markets, for example, in the markets of telecommunications services, raises the issue of regulating the economic competition of telecommunications operators in the interconnection of telecommunications networks and the provision of telecommunications services. In the telecommunications industry, it is useful to take into account the experience of applying various mechanisms of antitrust and competitive regulation of various industries or markets in countries around the world.
According to the Decision of the National Commission for State Regulation of Communications and Informatization (NCCIR) No. 640 dated December 11, 2018, registered with the Ministry of Justice of Ukraine on January 17, 2019 according to No. 54/33025 "On Approval of the Procedure for Analyzing the Markets of Certain Telecommunications Services and Determining Operators, Telecommunications Providers with a Significant Market Advantage in the Markets of Such Services" assessment of the state of economic competition in the market of telecommunications services NCCIR to establish the expediency of determining operators, providers

Corresponding author:

${ }^{1}$ Ukrainian State University of Chemical Technology, Ukraine.

E-mail: myachin2020fuzzy@gmail.com

ORCID: https://orcid.org/0000-0002-1491-5100

${ }^{2}$ Dnipro Humanitarian University, Ukraine.

E-mail: el.judina@gmail.com

ORCID: https://orcid.org/ 0000-0003-3699-5321

ResearcherID: https://publons.com/researcher/4350920/olena-yudina 
with a significant market advantage, to which the obligations established by law will apply, evaluates the state of economic competition in the market of certain services according to three criteria:

1) the level of market concentration (concentration of the share of income from the provision of services in the service market for a certain number of operators, providers of such services);

2) the presence of significant (high and constant) barriers to entry into the market of services of other operators, providers;

3) the presence of problems that exist in the markets of telecommunications services, regarding the regulation of interaction of telecommunications operators when connecting telecommunications networks and providing telecommunications services (starting a connection, passing traffic, access to telecommunications networks, providing telecommunication channels for use), the solution of which falls within the competence of NCCIR and which cannot be solved in full only with the application of legislation on the protection of Economic Competition.

\section{Methods of studying the level of concentration and monopolization of the market}

When analyzing antimonopoly and competition regulation, in particular, in the telecommunications industry, it will be useful to take into account the experience of applying various mechanisms of antimonopoly and competition regulation in various industries or markets in the world. In the United States, the level of concentration and monopolization of the market is determined using the Herfindal or Herfindal-Hirschmann index and the Concentration Ratio, which are effective tools for antitrust regulation. The Herfindahl-Hirschman Index is designated as HHI (the Herfindahl-Hirschman Index), and the Concentration Ratio as CR (Concentration Ratio).

The definition of the HHI index is used to analyze the level of competition and takes into account the market share of each participant (Posner, 1999).

When analyzing competition, this indicator reacts to the share of each business entity in the market. The procedure for calculating it consists in determining the sum of squares of interest of each subject in the market or in the industry:

$$
H H I=S_{1}^{2}+S_{2}^{2}+\ldots+S_{n}^{2}=\sum_{i=1}^{N} S_{i}^{2},
$$

where $S_{i}$ is a market share of the $\mathrm{n}$ business entity (Pindyck, Rubinfeld, 2015).

The concentration ratio $C R$ is an indicator that shows the market share of a selected number of large business entities in the market or the sum of their market shares. The upper limit of this ratio is 100 , which means that the market is completely monopolized. In this respect, the concept of "set number" of business entities in the market is uncertain. To clarify this "set number" of large business entities in the market, this indicator is determined with a figure that characterizes this number of market players, for example, $C R 2, C R 5$ or $C R_{n}$, which means considering the share of 2,5 or $\mathrm{n}$ firms in the market, respectively:

$$
\mathrm{CRn}=\sum_{i=1}^{N} S_{i},
$$

where $C R_{n}$ is a concentration ratio of $n$ business entities in the market;

$S_{i}$ is the market shares of the largest companies (percentage).

\section{Features of the study of a significant market advantage in the telecommunications services market}

For the telecommunications industry, the market concentration coefficient is the sum of the largest shares of three operators and providers ranked in descending order of income received during the year in a certain service market.

According to the Decision discussed above (Arbabi, Tash, 2018), if the value of the market concentration ratio CR exceeds $45 \%$ and/or the value of $H H I$ exceeds 1000, the level of concentration in the market of certain services, which is analyzed, indicates that according to this criterion, the market is favourable for the application of preliminary regulation and there is a need to determine the presence of structural, strategic and administrative barriers to entering the market. However, this solution does not define a single, comprehensive indicator of markets in terms of their concentration (Pryputa, 2016).

As noted above, the value of $H H I$ is the basis for decision-making at the enterprise level. In addition to determining market concentration, $\mathrm{HHI}$ and $\mathrm{CR}$ serve as the basis for making M\&A decisions. They are the basis for characterizing markets in terms of concentration. In the USA, there are three types of markets based on this feature:

type I - markets with a low concentration ratio, the state of which is characterized by the value of the limits of the above indices: $C R<45 \%$; $H H I<1000$;

type II - markets with a middle concentration ratio, with the characteristics of coefficients: $45 \%<C R<70 \%$; $1000<H H I<1800$;

type III - markets with a high level of concentration, with the value of coefficients: $70 \%<C R<100 \%$; $1800<H H I<10000$.

In the United States, since 1982, HHI and CR have been legally approved as one of the most important indicators for assessing the permissibility of mergers and acquisitions in the process justification of 
antimonopoly legislation. The criterion for making decisions about the possibility of increasing the concentration ratio is the levels of $H H I$ and $C R$.

\section{Construction of an integral indicator for evaluating a market advantage indicator using the fuzzy logic apparatus}

Identifying the type of market structure is quite a complex task. This is largely due to the lack of clear boundaries of the criteria that separate them. Therefore, to determine the type of market structure, it makes sense to use the tools of Fuzzy Logic theory (Nikolaev, 2013).

The use of the method of applied mathematics based on the theory of fuzzy logic by L. Zadeh in economic research is a relatively new phenomenon (Arbabi, 2018).

In this case, the subjective assessment of the criterion for determining a particular type of market structure is based on its characteristics. One of the signs of the type of market structure is the number of sellers. In an oligopoly, there are a small number of large organizations - from 2 to 10 , in conditions of perfect competition - there are many (more than 100 units) organizations of equal size. The second feature that allows you to distinguish between market structures is the density of distribution of organizations' shares in the market (Tash, 2014).

Modern mathematical apparatus allows you to take into account several features and their types at once when using the Fuzzy Logic method, that is, it is quite possible to take into account all or the main indicators of concentration. In our opinion, it is advisable to take into account only one indicator - the HerfindalHirschman index - in order to avoid distortion. Its indisputable advantage is that it takes into account almost equally such concentration parameters as the number of organizations operating in the industry market and the degree of inequality in their market shares.

Taking into account that the upper limit of the Herfindal-Hirschman index is 10,000, and the lower limit tends to zero, then a clear set for the monopoly market will be the value $\mathrm{x}=10,000$, for an oligopoly $\mathrm{x} \in[1000$; $5000]$, for perfect competition $\mathrm{x} \in[0 ; 1000]$ ( $x$ is the base variable).

Thus, to implement a fuzzy-logical approach to determine the integral indicator of enterprise market concentration $(M C)$, we have selected the main groups of input indicators that affect the target indicator, namely: the Herfindal-Hirschman index (HHI) and the Concentration ratio of the business entities in the market $\left(C R_{n}\right)$.

Since then, intellectual system development based on multicriterial methods of fuzzy sets theory as well as on the models of multidimensional analysis of economic systems is vital for economic decision making about market concentration.

Figure 1 introduces general layout of fuzzy expert system as a transformation of data inside the system itself.

Next phase of the fuzzy expert system construction is based on membership function selection. Fuzzy model rather complicates the model if based on a significant quantity of input variables which is actually illustrated further. Due to the fact, input variables quantity requires substantiated optimal reduction. Furthermore, membership function requests for relevant correction considering aforementioned reduction; anyhow, range of the values should be kept unchanged for linguistic description of the variables for every input value (Korol, 2012).

"Bell"-shaped membership function has a layout of a symmetric curve which resembles shape of the bell. This function is set by the formula which parameters are interpreted as follows:

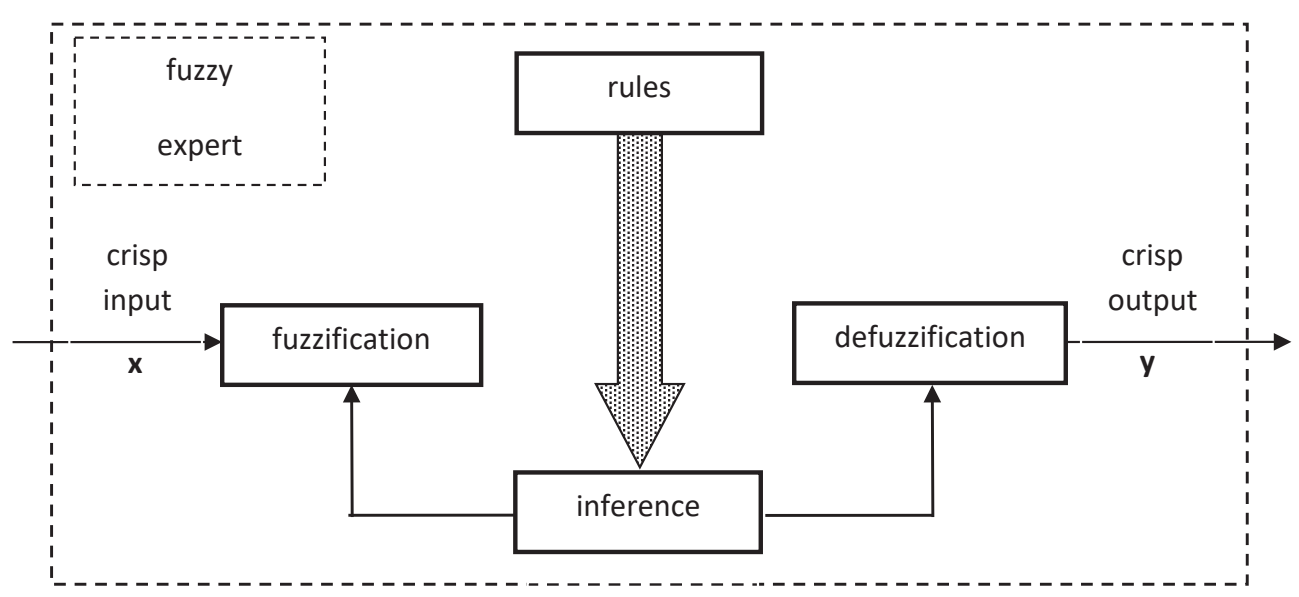

$y=f(x)$

Figure 1. General layout of fuzzy expert system 
Table 1

Correlation between the quantity of the model fuzzy rules which secure model completeness and model inputs (input variables) $\omega$ as well as the quantity of $z$ fuzzy sets in every input

\begin{tabular}{|c|c|c|c|c|c|}
\hline \multirow{2}{*}{$\begin{array}{c}\text { Quantity of } \mathrm{z} \text { fuzzy } \\
\text { sets at every input }\end{array}$} & \multicolumn{5}{|c|}{ Quantity of the model $\omega$ inputs (quantity of the input variables) } \\
\cline { 2 - 6 } & $\omega=1$ & $\omega=2$ & $\omega=3$ & $\omega=4$ & 1 \\
\hline$z=1$ & 1 & 1 & 8 & 16 & 3 \\
\hline$z=2$ & 2 & 4 & 27 & 81 & 243 \\
\hline$z=3$ & 3 & 9 & 64 & 256 & 1024 \\
\hline$z=4$ & 4 & 16 & 125 & 625 & 3125 \\
\hline$z=5$ & 5 & 25 & & & \\
\hline
\end{tabular}

$$
\mu(x)=\frac{1}{1+\left|\frac{x-c}{a}\right|^{2 b}},
$$

where $a$ is a concentration ratio of the membership function; $b$ is a curvature ratio of the membership function; $c$ is a maximum coordinate of the membership function.

Next phase of the fuzzy model construction is the identification of fuzzy logic rules. Considering that quantity of the model inputs (input variables) is $\omega$ and every input has $z$ of fuzzy sets (membership functions) then the quantity of fuzzy logic rules can be defined through the following formula:

$$
r=z^{\omega} \text {. }
$$

Table 1 introduces correlation between the quantity of the model fuzzy rules which secure model completeness and model inputs (input variables) $\omega$ as well as the quantity of $z$ fuzzy sets in every input. Table 1 demonstrates that increasing quantity of the model inputs (input variables) $\omega$ along with increasing quantity of $z$ fuzzy sets results in fuzzy rules increase which makes the model construction quite an intense (Pegat, 2009).

The quantity of fuzzy sets at every input is considered as $z=3$, the quantity of input variables is considered as $\omega=2$. Then the quantity of fuzzy logic rules should result in $r=3^{2}=9$ to secure the model completeness.
Modelling of an integral degree of market concentration has been executed in in Fuzzy Logic Toolbox software of MATLAB environment (version R2015B) by MathWorks company which has affected setting and view of the "bell"-shaped membership function. The setting of the function is as follows: $\mu(\mathrm{x})=\operatorname{gbellmf}(x,[a b c]) \cdot x$ is an input variable, $a, b$ and $\mathrm{c}$ are aforementioned parameters (formula (3)).

Next figures 2-4 introduce attributes and membership functions for two input variables and one output variable. Figure 2 introduces $C R$ input variable which is a concentration ratio and has three attributes (membership functions): Low - low concentration, Middle - middle concentration, High - high concentration. This function is "bell"-shaped and has value rate $[0 ; 100]$. Low membership function means that low concentration has parameters [45 2.5 -0.108], Middle membership function means that middle concentration has parameters [ 13.9 1.57 60], High membership function means that high concentration has parameters [ 25.512 .5100$]$.

Figure 3 introduces input variable HHI ("the Herfindahl-Hirschman index") has three attributes (membership functions): Low - low HHI level, Middle - middle HHI level, High - high HHI level. This function is "bell"-shaped and has value rate $[0 ; 10000]$. Low membership function means that low HHI level has parameters [550 2.5 20.1], Middle membership function means that middle $H H I$ level

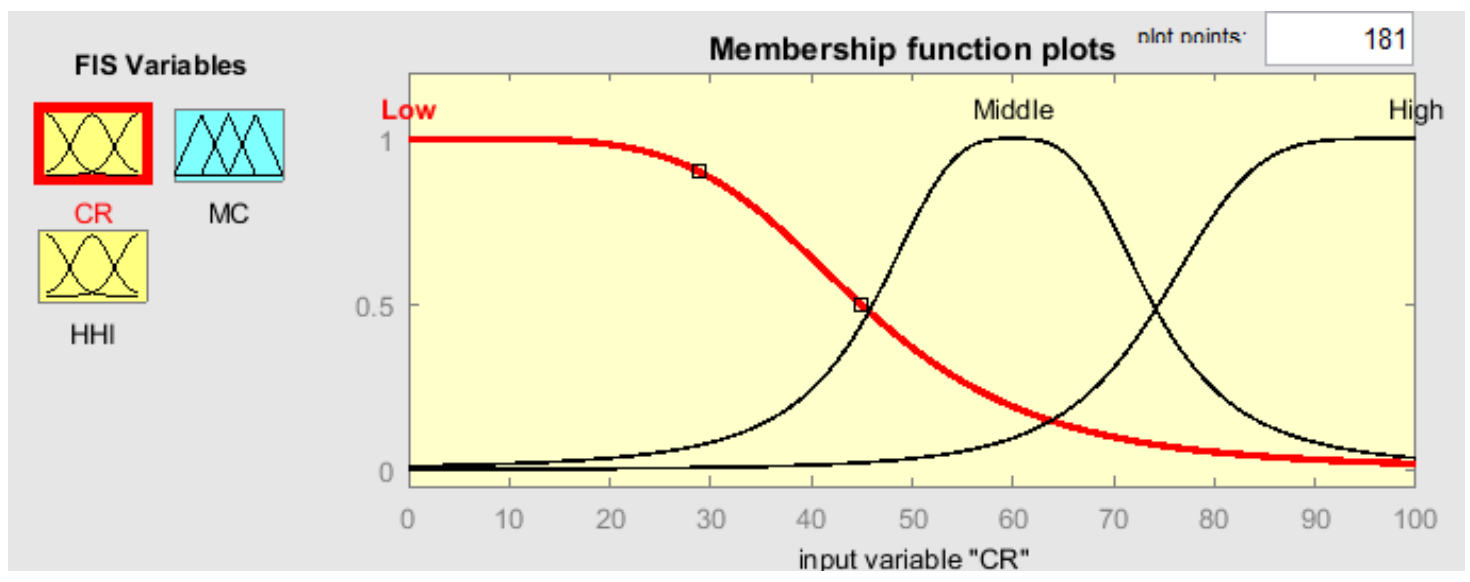

Figure 2. Membership function chart for input linguistic variable CR (concentration ratio) 


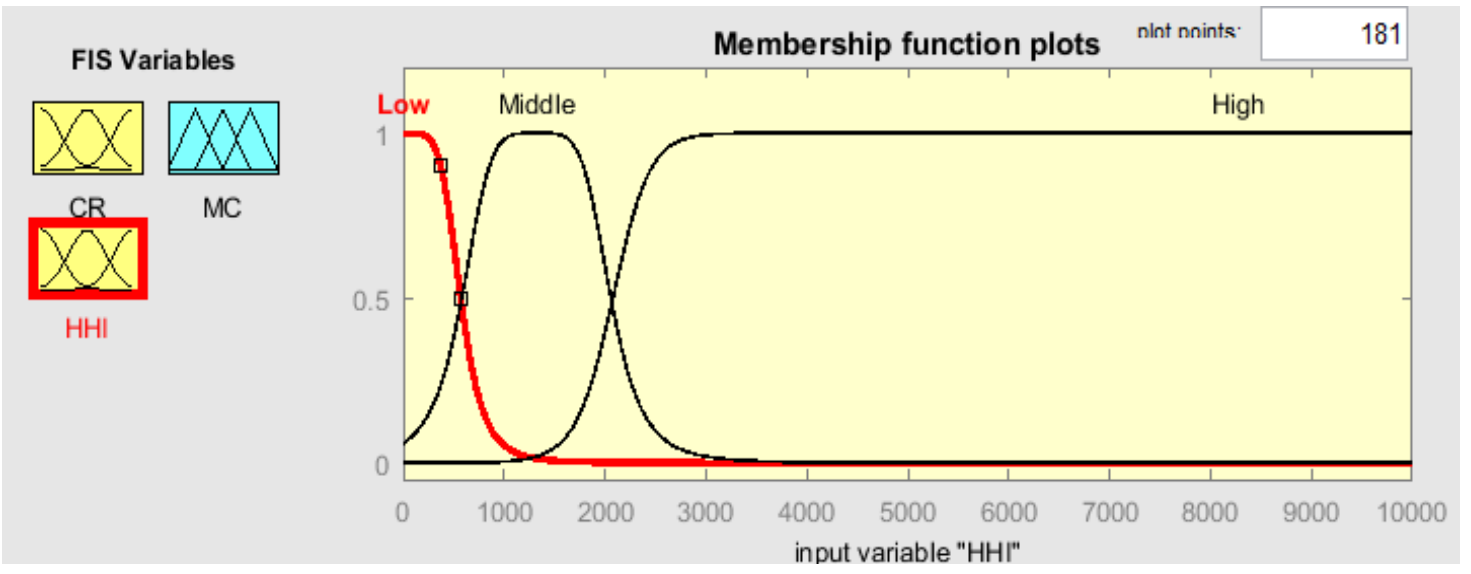

Figure 3. Membership function chart for input linguistic variable HHI ("the Herfindahl-Hirschman index")

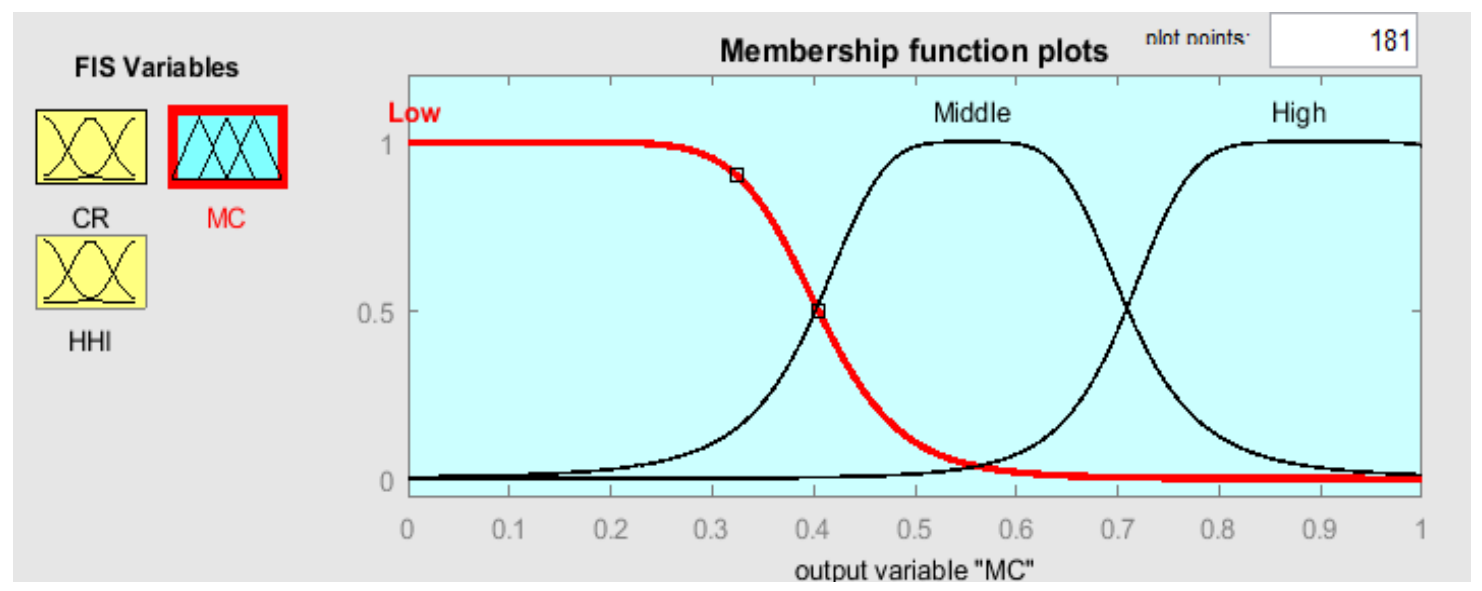

Figure 4. Membership function chart for output linguistic variable MC (market concentration)

has parameters [ $\left.\begin{array}{lll}739 & 2.38 & 1320\end{array}\right]$, High membership function which means high $H H I$ level has parameters [7452 20.39530$]$.

Figure 4 introduces output variable $M C$ (market concentration) and has three attributes (membership functions): Low has parameters [0.4046 $4.976 .94 \mathrm{e}-$ $18]$, Middle has parameters [0.154 2.110 .556$]$, High has parameters [ 0.22 .950 .908$]$. This function is "bell"shaped and has value rate $[0 ; 1]$.

Based on the description of two-input and oneoutput variables we have defined $3^{2}=9$ fuzzy rules for the output variable conclusion.

Fuzzy logic rules are laid out as follows:

Rule 1: If ( $\mathrm{CR}$ is Low) and (HHI is Low) then (MC is Low);

Rule 2: If (CR is Low) and (HHI is Middle) then (MC is Low);

Rule 3: If (CR is Low) and (HHI is High) then (MC is Middle);

Rule 4: If (CR is Middle) and (HHI is Low) then (MC is Middle);

Rule 5: If (CR is Middle) and (HHI is Middle) then ( $M C$ is Middle);
Rule 6: If (CR is Middle) and (HHI is High) then (MC is Middle);

Rule 7: If (CR is High) and (HHI is Low) then (MC is Middle);

Rule 8: If (CR is High) and (HHI is Middle) then (MC is High);

Rule 9: If (CR is High) and (HHI is High) then (MC is High).

Left column of Figure 5 introduces all 9 defined fuzzy rules and next two columns show $C R=10.6$ and $H H I=0.985$ for input values. $M C$ value shows off in the right column for every fuzzy rule as a degree of market concentration. For instance, output value of degree of market concentration is $M C=0.22$. Results are visualized in Matlab environment through Rule Viewer visualizer.

The constructed model of fuzzy conclusion allows to evaluate a degree of market concentration once MC indicator which is the concentration ratio and $\mathrm{HHI}$ indicator which is the Herfindahl-Hirschman index use have been set. Depending of output variable $M C$ which is a degree of market concentration on the input variables is proven by infinity of the $M C$ values represented as 


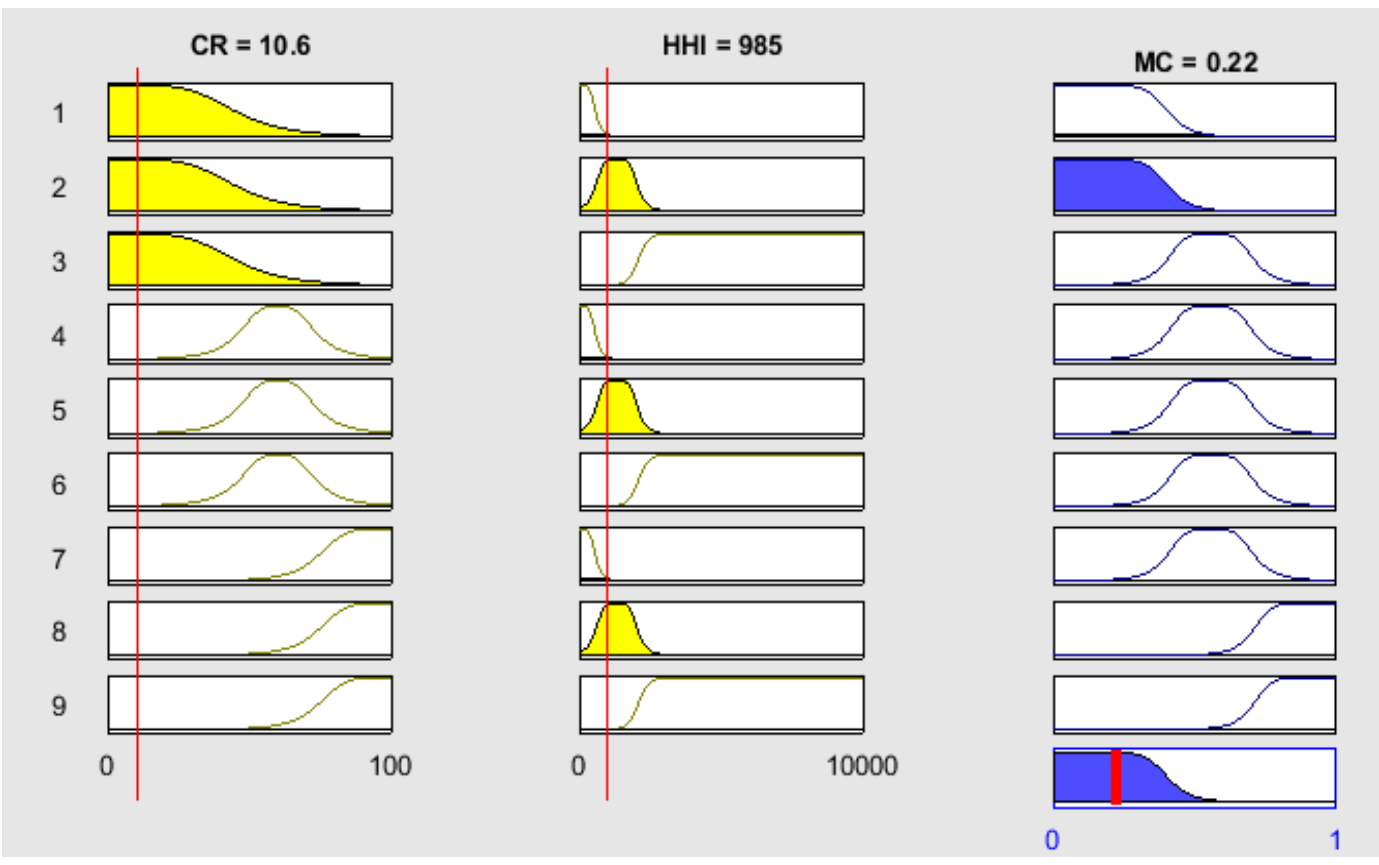

Figure 5. Implementation of Mamdani fuzzy conclusion in Fuzzy Logic Toolbox software of Matlab environment by MathWorks company for evaluation of a degree of market concentration

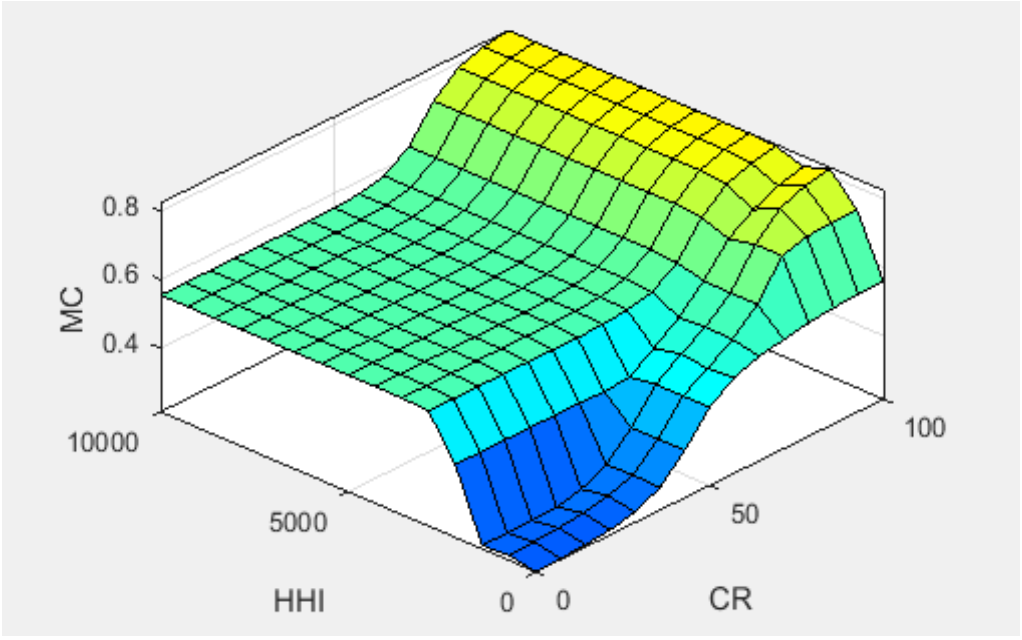

Figure 6. Depending of output variable MC, market concentration, on the input variable $C R$, concentration ratio, and input variable $H H I$, the Herfindahl-Hirschman index. Modelling results

a response surface constructed with Surface Viewer (Figure 6).

Visualization of "input-output" surface allows to define that output indicator $M C$, market concentration, reaches its maximum at maximum value of $C R$ indicator which is a concentration ratio along with big value of HHI which is a Herfindahl-Hirschman index.

\section{Conclusions}

Coming to a conclusion of all aforementioned it should be stated that to evaluate a degree of market concentration, methods of fuzzy sets are considered to be the most effective in comparison with linear models. Fuzzy model developed for evaluation a degree of market concentration allows to consider not only qualitative but also quantitative features of an industrial enterprise which are perceived to be set with obstacles or as the ones impossible to set. The model theoretically allows for engagement of significant quantity of the indicators. Nevertheless, the practical choice should be substantiated by the indicators weight on the one side and by the intense of data collection required to evaluate a degree of market concentration on the other side. 
To implement a fuzzy-logical approach to determine the integral indicator of market concentration $(M C)$, we have selected the main groups of input indicators that affect the target indicator, namely the Herfindal-Hirschman index (HHI) and the Concentration Index of business entities in the market $\left(C R_{n}\right)$.

Fuzzy logic model developed for evaluation of a degree of market concentration is executed in the following phases: 1) engagement of two integral indicators one of which describes concentration ratio while another one describes level of the HerfindahlHirschman index use; 2) selection of membership function parameters and type for two-input and the output variables; 3) development of the system of 9 rules; 4) calculation of a degree of market concentration using Mamdani fuzzy conclusion; 5) verification of the model adequacy.

\section{References:}

Arbabi, L., \& Tash, M. (2018). Study of the Relationship between Concentration, Skilled Labor and Efficiency Using the Fuzzy Logic Approach in Iranian Manufacturing Industries. The Open Access Journal of Resistive Economics (OAJRE), vol. 6, no. 4, pp. 1-18.

Gawronska, A., \& Gawronski, T. (2012). Assessment of bankruptcy threat of furniture manufacturing companies with fuzzy logic. Intercathedra, vol. 28(1), pp. 13-18.

Korol, T., \& Korodi, A. (2012). An evaluation of effectiveness of fuzzy logic model in predicting the business bankruptcy. Institute for Economic Forecasting, vol. 3, pp. 92-107.

Nikolaev, D. V. (2013). Metodicheskii podkhod k identifikatcii tipa rynochnoi strukttcry (na primere rynka ryboproduktcii Primorskogo kraia) [Methodological approach to identifying the type of market structure (on the example of the fish market of Primorsky Krai)]. Forecasting problems, vol. 1, pp. 95-101.

Pegat, A. (2009). Nechetkoe modelirovanie i upravlenie [Fuzzy modelling and control]. Moscow: BINOM. Laboratoriia znanii [BINOMIAL. Knowledge lab], 798 p.

Posner, R. A. (1999). Natural Monopoly and its Regulation. Washington DC., Cato Institute, 115 p.

Pro zatverdzhennia Poriadku provedennia analizu rynkiv pevnykh telekomunikatsiinykh posluh ta vyznachennia operatoriv, provaideriv telekomunikatsii z istotnoiu rynkovoiu perevahoiu na rynkakh takykh posluh [On approval of the procedure for analysing the markets of certain telecommunications services and identifying operators and telecommunications providers with a significant market advantage in the markets of such services]. Cabinet of Ministers of Ukraine. Available at: https:/ /zakon.rada.gov.ua/laws/show/z0054-19\#n33

Pryputa, T. (2016). Methodological approaches to assessing the level of monopolization in the economy. Scientific Bulletin of Mukachevo State University. Economy Series, vol. 1(5), pp. 51-55.

Sivanandam, S. N., \& Sumathi, S. D. S. (2006). Introduction to Fuzzy Logic using MATLAB. Springer-Verlag Berlin Heidelberg, $430 \mathrm{p}$.

Tash, M., Molaei, S., \& Barghandan, K. (2014). Impact of Structural Components of Market on the Markup Level Based on Radial Basis Neural Network and Fuzzy Logic. International Journal of Business and Development Studies, vol. 6, no. 1, pp. 99-112. 